\title{
Violência das armas, violência no gênero: campo fértil das desigualdades
}

\author{
Claudio Bartolomeu Lopes
}

Pontifícia Universidade Católica de São Paulo (PUC-SP)

Violência das armas, violência no gênero: campo fértil das desigualdades

Resumo: O presente artigo busca mostrar como o cenário de guerra pode implicar e resultar em situações de violência e desigualdade no gênero. Procura-se mostrar como a luta pela independência do país, seguida por quase três décadas de conflito civil, influenciou e, até mesmo hoje, influencia a manutenção de um contexto de desigualdade na existência diária da mulher angolana. Inseridas nesse contexto de lutas, estas mulheres, ao mesmo tempo, buscam caminhos para levarem a cabo uma nova luta: a luta pelo reconhecimento de seus direitos. Uma luta com letras, uma luta por direitos, uma luta pela sua autonomia.

Palavras-chave: violência, cultura, gênero, desigualdade, relações igualitárias.

\section{The Violence of Guns and Gender Violence: a Fertile Field for Inequality}

Abstract: This article shows how war can stimulate and be related to gender violence and inequality. It shows how the Angolan independence struggle, followed by nearly three decades of civil conflict, has influenced inequality in the daily existence of Angolan women. Inserted in this context of struggle, these women simultaneously seek routes to undertake a new struggle: the struggle for recognition of their rights. This is a struggle waged with letters, a struggle for rights, a struggle for autonomy.

Key words: violence, culture, gender, inequality, egalitarian relations. 
Ainda adolescente, fui iniciada nas ideias revolucionarias, aderi sem saber o porquê das coisas. Saí de casa aos 17 anos. Sai do leite para a massambala ${ }^{1}$. Não sabia comer à mão. Tinha que comer rápido, porque se demorasse, os outros acabariam a comida. E o funge ${ }^{2}$ estava tão quente! Acabei aprendendo. Mas nunca me arrependi.

Para mim foi uma experiência que só acontece uma única vez e durante um tempo determinado na vida de uma pessoa. Aprendi muito, e hoje posso dizer que me sinto realizada. Madura. Experiente. Sei coisas sobre tácticas militares, sobre armas, sobre métodos de prevenção. Quando lanço os olhos para longe, sei que do outro lado existem vidas, o horizonte para mim já não tem segredos. Posso dizer que sou capaz de me defender com sabedoria e não mais com armas. Sei convencer... ${ }^{3}$

Para abordar o tema proposto, considero importante esclarecer ao leitor que estarei fazendo uma abordagem crítica a partir da experiência por mim vivida quando trabalhei para o sistema das Nações Unidas em Angola e para organizações humanitárias internacionais, durante os anos de 1996 a 2008, desempenhando funções de reintegração social, nas áreas econômica e profissional, na coordenação das ajudas humanitárias e nos processos de reassentamentos populacionais, e, por fim, como oficial de direitos humanos.

É necessário, também, esclarecer que este artigo não é exclusivamente um trabalho acadêmico, é mais a contextualização de uma experiência acumulada ao longo de mais de uma década em um ambiente que se permeou vários processos, de paz, guerra, reintegração social, abusos de direitos humanos, entre outros. Onde, muito de perto, vivenciei os problemas enfrentados pelas mulheres de Angola.

A concepção deste ensaio só foi possível devido à construção histórica que os sujeitos, que dele fazem parte, emprestaram-me, na sua voz, na sua narrativa, na sua história. Foi esse conhecimento que tornou possível dar a consistência científica necessária que reveste este artigo. Assim, cabe ressaltar, que foram respeitados todos os pressupostos e princípios éticos, em se tratando de relatos de seres humanos acordados, seja nacional ou internacionalmen$t^{4}$, e que todos os depoimentos aqui registrados foram devidamente autorizados para publicação pelos depoentes ou entrevistados em nível de consentimento livre e esclarecido.

Dentro deste marco histórico, traço algumas considerações relevantes sobre alguns aspectos da história de Angola, e como pude compreender a participação das mulheres angolanas dentro deste processo. Tal participação foi efetiva e contribuiu para que Angola se tornasse independente do jugo colonial e enfrentasse aproximadamente três décadas de conflito civil (1975-2002). E, ainda, que retomasse um proces- so de paz e de reconstrução nacional sem, contudo, garantir às mulheres, enquanto sujeitos históricos e ativos, uma relação de igualdade para com os homens.

Desde o princípio do processo da colonização (século 16) de Angola pelos portugueses até a contemporaneidade, podemos verificar que o povo angolano vem travando imensas lutas pela demarcação e independência de seu território, culminando assim com a emancipação da metrópole portuguesa em 1975.

Deste processo de independência, uma nova luta passa a ser travada entre os próprios angolanos culminando com uma guerra civil de quase três décadas (1975-2002) que ceifou e ou mutilou a vida de milhares de cidadãos angolanos, em especial as mulheres, as crianças e os idosos.

Neste contexto histórico, a mulher angolana teve um papel fundamental em diferentes momentos e situações; seja político, econômico, social ou cultural onde se fez prevalecer a sua garra, coragem e ousadia, através de processos de negociação política, enfileiramento junto às tropas em defesa da pátria, e manutenção das necessidades básicas de sua família e agregados, seja através do trabalho formal ou informal, como mãe, como guerrilheira, como militar ou apenas como mulher.

No decorrer destas lutas pela efetivação de um Estado que pretendia ser democrático, muitas formas de desigualdades foram sendo patenteadas ao longo deste interminável percurso, como a desigualdade social, econômica, política, étnica, de gênero e ainda territorial.

Podemos dizer que a desigualdade marcada pelo território perpassa por todas as demais, pois dependendo da localização do sujeito no território, também dependerão as demais condições de inclusão ou exclusão, independentemente de ser homem ou mulher.

Enquanto persistiam as intensas lutas em busca do poder por parte das duas frentes protagonistas, sendo, de um lado, o governo, representado pelo Movimento Popular de Libertação de Angola (MPLA) e de outro a guerrilha representada pela União Total pela Libertação de Angola (UNITA), quem mais sofria eram as mulheres e as meninas que, constantemente, eram violentadas e violadas de seus direitos mais primordiais nas suas mais diferentes formas.

Enquanto comunidades inteiras sofrem as consequências do conflito armado e terrorismo, mulheres e meninas são particularmente afetadas por causa de seu status na sociedade e de seu sexo. Partes do conflito frequentemente estupram mulheres com impunidade, algumas vezes usando estupros sistemáticos como uma tática de guerra e terrorismo. O impacto da violência contra as mulheres e violação dos direitos humanos das mulheres em certas situações é vivenciado por mulheres de todas as 
idades, que sofrem deslocamentos, perda de sua casa e propriedade, perda ou desaparecimento involuntário de parentes próximos, pobreza, separação e desintegração familiar, e que são vítimas de atos de assassinatos, terrorismo, tortura, desaparecimento involuntário, escrava sexual, estupros, abuso sexual e gravidez forçada em situação de conflito armado, especialmente como um resultado de políticas de limpeza étnica e outras novas formas de violência que emergem. Isto é composto por uma longa vida social, econômica e psicologicamente traumática, consequências de conflitos armados e ocupação estrangeira (IV CONFERÊNCIA MUNDIAL SOBRE A MULHER, 1995, p. 57).

As quase três décadas de conflitos armados fizeram com que aproximadamente quatro milhões de pessoas em Angola se tornassem deslocados internos, sendo em sua maioria as famílias chefiadas por mulheres. Situação devida ao fato de que os homens estavam empenhados em defender as suas posições políticas partidárias através do confronto armado, já que o mundo das ideias estava longe de ser uma realidade, ao menos consensual.

Neste cenário que agonizava com o aumento da pobreza, com milhões de deslocados - onde tudo se tentava para amenizar a fome, as doenças, as privações e, em especial, a violência contra as mulheres - mais visível se tornava a desigualdade entre os que tinham que fugir de suas áreas de origem para os campos de deslocados e os que estavam dentro das estruturas militares, paramilitares, membros do governo, funcionários das empresas petrolíferas e diamantíferas, e até mesmo em relação àqueles que faziam a exploração ilegal de diamantes, o que, por vezes, era facilitado pela própria situação de guerra.

Apesar de as mulheres serem o alvo mais atingido pela violência e pela solidificação das desigualdades elas conseguiram, ainda assim, exercer um grande papel em parceria com os homens nas lutas pela independência e pela democratização do país. Esta parceria, contudo, estabelecida ainda hoje, não foi reconhecida pelos homens, seus companheiros de caminhada. Nem tampouco pelo próprio Estado, que não propiciou às mulheres as mesmas condições de reintegração social, política e econômica na sociedade, proporcinada a outros cidadãos, deixando-as numa posição de inferioridade e até mesmo de exclusão social.
Para Faustina Naievele, Secretária Adjunta da Organização da Mulher Angolana (OMA), por parte do governo, na Província de Bié, "a OMA desde sempre nos tempos dos maquis ${ }^{5}$, lutou lado a lado com os homens em todos os sentidos, mesmo em guerra a OMA sempre ajudou o homem". Evidencia-se assim o quanto as organizações de mulheres, tanto do lado do governo como da guerrilha, ajudaram os homens, seja como carregadoras de armamentos e munições, seja como mobilizadoras, cozinheiras e até mesmo na linha de frente dos combates. Ao conhecerem a paz, em fevereiro de 2002, foram literalmente traídas em relação ao reconhecimento de seu papel na sociedade e em relação aos ideais que defendiam.

O não reconhecimento deste esforço bravio e sem medidas pelos homens e pelo Estado colocou essas mulheres em uma situação de desigualdade, obrigando-as a se inserir, hoje, a um mercado informal e totalmente desre-gulado. Precisam vender nas esquinas dos mercados, atuar como zungueiras $^{6}$ nas ruas, sem, contudo atingir as condições mínimas para o sustento de seus próprios filhos e/ou agregados. Essa foi a retribuição depois de todo o compromisso e do ideal de relações igualitárias por assumidos.

Pode constatar esse tratamento e essa situação nos depoimentos reunidos em Chiziane (2008, p. 111-112), nas palavras de uma ex-militar:

\section{Apesar de as mulheres serem o alvo mais atingido pela parceria com os homens nas lutas pela independência e pela democratização do país.}

Frequentei a Escola de Instrução Militar durante seis meses onde terminei com a melhor classificação. Os meus colegas, menos qualificados que eu, foram patenteados, menos eu, que era mulher. Quando regressei à minha unidade, fui promovida para membro do Estado-Maior, como chefe das relações públicas e orientadora de círculos de estudos de uma das Instituições Militares da $5^{\text {a }}$ Região.

Consumi a minha vida de arma na mão, ao lado de homens, mas o meu esforço não foi reconhecido. Muitos colegas menos competentes do que eu foram promovidos e patenteados só por serem homens e hoje vivem bem. Fui discriminada na família. Na sociedade. Nas fileiras onde dediquei a minha juventude e toda a minha melhor energia. A discriminação existe em todo o lado, mas é no exército que se faz sentir com maior intensidade. $\mathrm{O}$ mundo das armas foi sempre o santuário dos homens. Eles defendem-no. Até parece que têm medo que as mulheres penetrem. 
Realidade semelhante, observa-se nas palavra de uma ex-guerrilheira:

Depois da guerra, a situação das mulheres é deplorável. Enquanto estávamos na guerrilha éramos todas iguais, éramos úteis. Hoje, os meus antigos subordinados passam por mim em bons carros, realizados, apenas porque são homens. Eu vendo aqui no mercado da esquina e nem tenho o suficiente para sustentar os meus filhos.

Nas negociações de paz, nós, mulheres, combatentes fomos esquecidas. Quando registraram os desmobilizados escreveram apenas os homens. Nós, mulheres, fomos completamente excluídas nesse processo, e fomos afastadas. Quando começamos a reclamar, simplesmente nos disseram que devíamos ir ao Ministério da Mulher, porque fomos incluídas nos grupos sociais das mulheres vulneráveis. Não imaginam como nos sentimos! É como se tivéssemos sido apunhaladas pelos nossos melhores amigos! (CHIZIANE, 2008, p. 140).

No que se refere à forma desigual em que homens e mulheres foram tratados durante os acordos de paz, tornou-se evidente a própria violentação do papel e do status social que a mulher possuía, deixando de ser um sujeito histórico e de poder para tornar-se parte dos grupos sociais vulneráveis. Dentro deste contexto, elas foram equiparadas aos idosos, crianças e pessoas com deficiência, que, em suma, são consideradas de pouca valia, já que não fazem parte efetiva da cadeia produtiva, o que reforça um tratamento discriminatório e excludente.

Segundo Castel, (1997, p. 21) "[...] a exclusão nomeia, atualmente, situações que traduzem uma degradação relacionada a um posicionamento anterior", esta degradação de posição a que as mulheres são constantemente colocadas, afeta diretamente não só a si, mas também a família e a própria sociedade.

Essas mulheres, que eram consideradas forças ativas e com papel bem definido, hoje são vulneráveis, são pobres, sem o acesso devido a bens e serviços, e foram empurradas ainda mais para o caminho da pobreza, e "[...] a desigualdade potencializa a discriminação de gênero, raça ou casta e geralmente tem a sua origem na própria discriminação" (GREEN, 2009, p. 4).

Podemos considerar que esta situação de desigualdade possui ainda um aspecto cultural, que se fundamenta na visão patriarcal onde o homem tem o poder absoluto, sobretudo, sobre aqueles que se mantêm sob o seu teto e seu olhar vigilante, acentuado ainda pelo exercício deste poder através das mais manifestadas formas de violência.

A organização social de gênero baseada na virilidade como força-potência-dominação, permite prever que há um desencontro amoroso marcado en- tre homens e mulheres. As violências física, sexual, emocional e moral não ocorrem isoladamente. Qualquer que seja a forma assumida pela agressão, a violência emocional está sempre presente (SAFFIOTI, 2004, p 75).

Este aspecto da cultura faz com que as mulheres vivam na subalternidade e, muitas vezes, em situação de opressão. Uma situação que encontra suas origens culturais na reflexão de Toledo (2008, p 23):

\begin{abstract}
A mulher nasce e é educada para ser oprimida, para saber 'o seu lugar' no mundo, que é sempre, em qualquer âmbito, um lugar subalterno. É configurada para aceitar essa condição como se fosse algo natural e, ainda por cima, com um sorriso nos lábios; contido, claro. Essa ideia, que a imensa maioria das mulheres introjeta sem qualquer tipo de questionamento, assenta-se na função maternal da mulher para justificar uma desigualdade entre os sexos e uma posição degradante que elas vêm suportando, com maior ou menor intensidade, desde o surgimento de formas mais ou menos estruturais de exploração entre os seres humanos.
\end{abstract}

É correto afirmar que em todo o mundo vem sendo efetuado um ardoroso trabalho para que relações igualitárias de gênero tornem-se uma realidade. Acesso ao mercado de trabalho, saúde, educação, outros bens e serviços e políticas contra a violência no gênero são, em geral, o carro chefe de toda essa luta, incluindo ainda as questões que perpassam pelos aspectos étnico-raciais.

Contudo, um aspecto importante, que muitas vezes tem sido deixado ou relegado a um segundo plano, é a questão cultural, ou ainda o contexto cultural em que esta luta está inserida, e por que não dizer o contexto cultural em que se tenta efetivá-la. A cultura de um determinado local, de um país ou de um continente exerce sobre as demais características uma enorme pressão que pode levar à falência qualquer forma de ação que busque tratar das relações igualitárias. No contexto africano, em especial, é a cultura das diferentes etnias que ainda prevalecem sobre quaisquer outros aspectos, principalmente no âmbito da efetivação de direito.

Apesar de os Estados membros da ONU assumirem o compromisso de se empenharem em reduzir a discriminação contra as mulheres e efetivar os direitos de igualdade, o que foi acordado e registrado através do documento Convenção das Nações Unidas sobre a Eliminação de Todas as Formas de Discriminação contra as Mulheres (1979, online), com enfoque principal em seu artigo 5, onde se lê:

Os Estados Partes tomam todas as medidas apropriadas para: a) Modificar os esquemas e modelos de 
comportamento sociocultural dos homens e das mulheres com vista a alcançar a eliminação dos preconceitos e das práticas costumeiras, ou de qualquer outro tipo, que se fundem na ideia de inferioridade ou de superioridade de um ou de outro sexo ou de um papel estereotipado dos homens e das mulheres.

A despeito dessas determinações, e de outras que compõem o documento, pouca visibilidade ou quase nada pode ser visto em termos de políticas públicas que tenha como objetivo abordar este aspecto da cultura.

Se abordassem e se se dispusessem a enfrentar as questões culturais que criam condições de desigualdade entre homens e mulheres, os governos certamente estariam a caminhar para mudanças de amplo realce e que poderiam ser mais efetivas que tentar ignorar os comportamentos e padrões culturais regionais, especialmente em países em conflito, ou em situação de pós-guerra.

O respeito pela diversidade e cultura dos Povos é, sem dúvida, um dos vetores essenciais de qualquer política de desenvolvimento social. É tanto assim que em 1969, a Organização das Nações Unidas para a Educação, a Ciência e a Cultura (UNESCO) introduziu a noção de 'políticas culturais', apelando aos governos para, explicitamente, reconhecerem as ações culturais como um importante fim da política pública (ROQUE, 2007, p. 122).

A violência no gênero, em especial contra as mulheres, é uma das formas mais notórias de desigualdade. Está centrada numa relação de força, opressão e valores culturais dominantes em relação a um sexo contra o outro, aquele que geralmente encontra-se numa posição inferior, de subalternidade e sem uma visão positiva em relação às possibilidades de criar mecanismos que facilite a alteração deste cenário.

É muito comum ver em diferentes artigos científicos, conferências, livros que se referem à questão da violência que ela é mais facilmente encontrada nas famílias, nos países, ou nos continentes onde se tem um grau de pobreza mais acentuado. Contudo, convém observar que a violência no gênero está presente não só nas camadas pobres mas também nas outras diferentes classes sociais, o que concorre para degradar o tecido social e, em especial, o familiar.

Para Roque (2007, p.121), “[...] nos países africanos mais pobres e/ou em conflito, para além da fome, da pobreza extrema e da desigualdade no gênero, a degradação do tecido familiar é uma realidade generalizada."

Esta degradação generalizada é ainda acentuada com os problemas gerados por uma sociedade que, apesar de ser oficialmente monogâmica, possui características marcantes da poligamia, pois é socialmente e culturalmente aceitável que um ho- mem possa ter mais de uma mulher, co-habitando, ou não, com ela. Apesar da importância do elemento feminino em todas as situações da vida, esta tendência ao comportamento poligâmico também influencia diretamente na visão que a sociedade em geral possui do papel da mulher, colocando-a numa posição de passividade e submissão.

Um grande empenho tem sido feito pelo governo e, principalmente, pelas organizações femininas sejam estas de caráter político partidário, vinculadas aos diferentes credos religiosos, ou às organizações não governamentais angolanas ou de âmbito internacional - no sentido de sensibilizar e motivar as mulheres para juntas lutarem contra todas as formas de discriminação e de desigualdade. Contudo, um longo caminho ainda precisa ser percorrido para que, este processo de transformação se consolide.

É de ressaltar que muitas áreas, em especial as rurais, ainda não possuem acesso ao mínimo necessário de serviços básicos, como a educação, saúde, informação, água e ações que possibilitem a participação comunitária, onde a mulher e o homem possam ter os mesmos direitos igualitários.

A mulher e o homem têm o mesmo ponto de partida, vivem os mesmos problemas, tanto sociais, políticos, econômicos, e desejam a mesma vida. E têm de ter os mesmos direitos e deveres, pois que todos fazem parte da mesma sociedade. Logo a mulher terá que perder o complexo de inferioridade, induzido pelo homem no tempo que a esposa era apenas um instrumento de procriação e escrava, um animal sem voz e nem ideias. A luta desencadeada pela mulher, hoje, está a conseguir patamar de relevo para a projeção significativa na sociedade.

A violência doméstica é a má interpretação do significado da emancipação e do adjetivo gênero. $\mathrm{O}$ regime deve encontrar fórmulas para a formação das mulheres, para a melhor interpretação dos direitos e deveres de todos os cidadãos. Não só a exclusão social na base dos seus direitos, da justiça, enfim, incentiva a violência doméstica que hoje está acentuada no país. Precisamos nos acautelar para resolver os problemas sociais oriundos da má vida econômica.?

Ao nos depararmos com mulheres em seus diferentes cotidianos, podemos ver claramente que elas possuem uma perspectiva positiva em relação ao futuro de suas vidas, e a forma de conseguir atingir um patamar mais elevado no que se refere à colocação no mercado de trabalho e à participação nos processos decisórios do país e de sua política: aumentando o seu grau acadêmico, através da educação formal.

E através da educação que elas pretendem transformar a sociedade, pois têm em mente que na sociedade angolana 
[...] há mulheres com capacidade, há mulheres com sabedoria, há mulheres com competência, [...] ela não é vulnerável, ela é ser humano, ela tem sentimentos, e quando ela consegue singrar na vida, ela é capaz, ela é capaz, [...] devemos dar as mãos umas as outras, porque sozinhas não vamos a sitio nenhum, e conseguir atualizar, atualizar-se para o bem estar mesmo da sociedade, porque uma mulher bem educada consegue educar aqueles que estão a sua volta, [...] e então educar bem os nossos filhos, é também ter uma sociedade bem educada. ${ }^{8}$

Apesar dessa intenção das mulheres em singrar na vida e conquistar mais espaço na sociedade por meio da educação, muitas delas veem este desejo interrompido antes mesmo de chegar ao ensino médio, pois, segundo a Direção Nacional para o Ensino Geral, em seu Relatório das Atividades Desenvolvidas no Gênero (REPÚBLICA DE ANGOLA, 2008a, p. 2), ainda uma grande parte das meninas deixam de estudar devido a situações de:

[...] pobreza das famílias, [...] gravidez precoce, pouca informação das famílias para a educação das meninas, [...] em algumas províncias o papel é de procriação e lida da casa, ajudar o marido na agricultura, [...] escolas muito distantes das comunidades.

No Diagnóstico sobre a Disparidade de Gênero nas Escolas do Ensino Primário e Primeiro Ciclo (REPÚBLICA DE ANGOLA, 2008b, p. 28), podemos ver que "o assédio dos professores às alunas" é também um elemento que contribui com a interrupção deste anseio feminino, demonstrando claramente a força do poder masculino até mesmo dentro da sala de aula, onde as forças e as armas para a defesa têm peso totalmente desigual.

$\mathrm{O}$ acesso à educação que deveria ser um direito de todos os homens e de todas as mulheres torna-se um privilégio da maioria dos homens em detrimento a uma minoria de mulheres que consegue transpor os obstáculos que lhes são impostos por conta da questão do gênero.

A priori, temos a impressão de que a situação da mulher angolana está mergulhada no caos total, mas, antes de definirmos essas circunstância, é importante que se leve em consideração os aspectos culturais e, principalmente, o processo de reconstrução nacional que está sendo executado no país.

É neste cenário controverso, que a mulher angolana, enquanto sujeito de si, tem buscado constantemente, incessantemente lutar por uma Angola de paz, com mais justiça social, onde haja oportunidades de estabelecer relações mais igualitárias.

A mulher angolana possui uma característica semelhante a uma fênix, quando se pensa que ela está a morrer, na realidade ela está a se refazer, a recuperar forças para retornar mais uma vez à luta e à labuta.

É este refazer que faz com que as mulheres, que sofreram todas as consequências de uma guerra que trouxe resultados drásticos à sua vida e a de seus familiares, encontrem e busquem nas experiências vividas o caminho para se colocarem em pé, de se organizarem, encontrarem aliadas e aliados para continuarem lutando, mas não numa guerra de armas, e sim numa guerra com letras: "Lutar com letras é lutar pela autonomia da mulher".

Toda essa situação aqui mencionada é muito significativa para desvelar o caráter e o espírito de luta da mulher angolana. Apesar de todos os meandros negativos - com quase nada de positivo - existentes nesta dúbia relação de gênero, a mulher africana, e, em especial, as angolanas não perdem o seu norte. Sabem sempre qual o caminho a tomar e como caminhar, mesmo que este seja um longo caminhar. Sabem como e quando avançar e recuar, recuar e avançar. Caminhos com pedras, sem pontes, sem asfalto, com minas terrestres, com implicações sociais, culturais, econômicas, políticas, religiosas... elas vão em frente.

No dia de ontem a mulher angolana tinha pouco valor, tinha pouco valor, mas agora já está a aparecer mais ou menos na sociedade porque está a estudar, porque não quer depender muito do homem. Nós já não queremos depender muito dos homens, então nós também já estamos a lutar mesmo. Estamos a lutar para podermos aparecer na sociedade, e já há muitos lugares que estão a ser ocupados pelas mulheres, o lugar de ministras, de governadoras, quer dizer de chefes máximos, já a mulher está a ocupar estes lugares, a mulher já esta a ocupar. ${ }^{10}$

\section{Referências}

IV CONFERÊNCIAMUNDIALSOBREAMULHER, 1995 Beijing, China. São Paulo: Editora Fiocruz/CNDM// Organização das Nações Unidas, 1996.

CASTEL, R. Desigualdade e a questão social. Tradução de Mariângela Belfiore Wanderlei e Cleisa Moreno Maffei Rosa. São Paulo: Educ, 1997.

CHIZIANE, P. (Org.). O livro da paz da mulher angolana - As heroínas sem nome. Luanda: Editorial Nzila, 2008. (Coleção Memórias, 6).

GREEN, D. Da pobreza ao poder - Como cidadãos ativos e estados efetivos podem mudar o mundo. São Paulo: Cortez, 2009. 
REPÚBLICADEANGOLA. Direção Nacional para o Ensino Geral de Angola. Relatório das atividades desenvolvidas no gênero, 2008a. Angola, 2008.

Direção Nacional para o Ensino Geral de Angola, 2008b. Diagnóstico sobe disparidade de gênero nas escolas do ensino primário e primeiro ciclo. Angola, 2008.

ROQUE, F. M. África, a NEPAD e o futuro. Angola: Texto Editores, 2007.

SAFFIOTI, H. I. B. Gênero, patriarcado, violência. São Paulo: Fundação Perseu Abramo, 2004.

CONVENÇÃO SOBREAELIMINAÇÃO de todas as formas de discriminação contra as mulheres. Dezembro de 1979. Disponível em: \http://www.cidadevirtual.pt/acnur/ refworld/refworld/legal/instrume/women/discr_p.htm>. Acesso em: 7 out. 2009.

\section{Notas}

1 Massambala: nome de um cereal semelhante ao sorgo que conhecemos no Brasil, do qual extraem a farinha para a confecção do funge de massambala.

2 Funge: prato principal das refeições confeccionado com fubá de milho, de mandioca ou de massambala, a depender da região e da etnia. No caso do milho é semelhante a uma polenta feita a base de água e fubá.

3 Depoimento de uma guerrilheira (CHIZIANE, 2008, p. 141).

4 Os dados que sustentam este artigo, estão respeitando os critérios constantes na Declaração de Helsinki (1975, revisada em 1983) e nas resoluções do Conselho nacional de Saúden. 196, de 10/10/96en. 251, de 07/08/97.

5 Maquis: movimento clandestino de resistência à colonização portuguesa.

6 Zungueiras, são mulheres que andam pelas ruas com bacias na cabeça, transportando produtos de primeira necessidade para serem vendidos de porta em porta.

7 Depoimentos colhidos em agosto de 2009 junto à representante da Liga da Mulher Angolana (LIMA) vinculada ao partido UNITAem Angola.

8 Depoimentos da Diretora Provincial da Direção da Administração Pública Emprego e Segurança Social (DAPESS-Bié), Angola, colhida em agosto de 2009.

9 Depoimento da senhora Isabel, uma cidadã angolana.
10 Depoimento de Maria Clara Tavares, outra cidadã angolana, em 5 ago. 2009.

\section{Claudio Bartolomeu Lopes}

lopescb@hotmail.com

Mestrando em Serviço Social pela Pontifícia Universidade Católica de São Paulo (PUC-SP)

Orientadora: Profa. Dra.Maria Lucia Martinelli

PUC-SP - Programa de Pós-Graduação em Serviço Social

Rua Ministro Godoi, 969, 4. andar

Perdizes - São Paulo

CEP: 05014-901 